\title{
Erratum to: MRI pattern of arthritis in systemic lupus erythematosus: a comparative study with rheumatoid arthritis and healthy subjects
}

Chiara Tani • Dario D'Aniello • Niccolò Possemato • Andrea Delle Sedie • Davide Caramella •

Stefano Bombardieri • Marta Mosca

Published online: 13 November 2014

(C) ISS 2014

Erratum to: Skeletal Radiol

DOI 10.1007/s00256-014-2033-0

The original version of this article unfortunately contained mistakes. The names of all authors were inadvertently inverted and are now corrected in the author group of this article.

The online version of the original article can be found at http://dx.doi.org/ 10.1007/s00256-014-2033-0.

C. Tani $(\bowtie) \cdot$ N. Possemato $\cdot$ A. Delle Sedie $\cdot$ S. Bombardieri $\cdot$

M. Mosca

Rheumatology Unit, Department of Clinical and Experimental

Medicine, University of Pisa, Pisa, Italy

e-mail: chiara.tani@for.unipi.it

D. D'Aniello $\cdot$ D. Caramella

Radiology Unit, University of Pisa, Pisa, Italy 